\title{
The effects on chicks of dietary fibre from different sources: a growth factor in wheat bran
}

\author{
BY S. N. HEGDE,* B. A. ROLLS, A. TURVEY AND \\ MARIE E. COATES \\ National Institute for Research in Dairying, Shinfield, Reading RG2 $9 A T$ \\ (Received I3 June I977-Accepted I9 December 1977)
}

\begin{abstract}
1. Groups of chicks were given a low-residue diet with or without supplements of dietary fibre in the form of wheat bran, wheat straw or bagasse. Growth and food conversion efficiency ( $g$ weight gained/g food eaten; FCE) during the first 4 weeks of life were measured.

2. In every one of seven experiments supplementation of the diet with $100 \mathrm{~g}$ wheat bran $/ \mathrm{kg}$ resulted in improved growth, and in three experiments FCE was also increased.

3. Supplementation with coarsely-milled wheat straw to provide an amount of unavailable carbohydrate equivalent to that in the bran diet resulted in poorer growth; finely-milled wheat straw had little effect on growth.

4. The growth-promoting effect of bran was destroyed by sterilization with heat or gamma-radiation.

5. In some experiments weights, lengths and volumes of small intestines were measured. Differences in intestinal dimensions between birds given the diet with and without fibre were not consistent, nor were they correlated with growth rate or FCE.

6. Histometric observations on small intestines from a few birds indicated that those given coarse wheat straw had longer villi and thicker muscularis layers, and the caecal tonsils had a greater area of lymphoid tissue and more follicles.
\end{abstract}

The nutritive value of dietary fibre for ruminant animals is well-known, but its importance to the nutrition of non-ruminant animals is poorly understood. Several earlier studies on chickens (Annison, Hill \& Kenworthy, 1968), pigs (Farrell \& Johnson, 1970), rabbits (Hoover \& Heitmann, 1972), rats (Yang, Manoharan \& Young, 1969) and ptarmigans (Lagopus mutus) (Gasaway, 1976a,b) have all indicated that there is little contribution from the caecal microbial fermentation of dietary fibre to the over-all energy budget of singlestomached animals. However, observations of Johnson \& McBee (I967) on porcupines (Erethizon dorsatum) and of Hoover \& Clarke (1972) on beavers (Castor canadensis) suggest that on diets high in fibre the caecal production of volatile fatty acids, if absorbed, could account for a significant proportion $(0 \cdot 16-0 \cdot 19)$ of the maintenance energy requirements of these animals.

Because of the physical characteristics of fibre, its inclusion in diets can modify gut function. For example, its water-holding capacity leads to more rapid transit of food through the gut and its absorptive properties may alter the availability of some nutrients (Eastwood, 1973). It can also have an abrasive action in the intestinal wall (Hallsworth \& Coates, 1962). Any or all of these factors could conceivably influence the efficiency with which a diet is utilized by the consumer.

The experiments reported here were part of an investigation into the importance of fibre in the nutrition of the chick. Wheat bran, wheat straw and bagasse (the fibrous by-product of the extraction of sugar from sugar cane, Saccharum officinarum) were chosen as sources of dietary fibre and used to supplement a low-residue diet of purified ingredients. Althougin the original intention was to study the effects on energy metabolism, an unexpected growth response to supplements of wheat bran was observed in a preliminary experiment, and the

* Present address: Department of Zoology, Karnatak University, Dharwar - 58003, India. 
main part of the work was directed towards elucidating this phenomenon. In some experiments the gross length, weight and volume of the small intestine were measured and its microscopic anatomy was studied to evaluate possible effects of dietary fibre on gut morphology.

\section{MATERIALS AND METHODS}

Chicks. Rhode Island Red $\times$ Light Sussex crossbreeds were maintained from $\mathrm{I} d$ of age in groups of ten in electrically-heated tier brooders, except in Expts $5 a$ and $6 a$, when they were housed in groups of four in cages in a controlled-environment room. Only chicks within a limited weight range were selected, and the sexes were matched as evenly as possible over the experimental treatments. Food and water were always available; lighting was supplied for I 4 h each day. All treatments were replicated at least three times, except in the exploratory test.

Diets. The low-residue basal diet of purified ingredients contained $(\mathrm{g} / \mathrm{kg}):$ maize starch $596 \cdot 5$, casein 180 , gelatin I00, salt mixture 60, L-cystine 3 , choline chloride I 5 , myo-inositol I, vitamin supplement 8 , maize oil 50 . The salt mixture provided ( $\mathrm{kg} \mathrm{diet}$ ): $\mathrm{CaCO}_{3}{ }_{17} \cdot \mathrm{I} \mathrm{g}$, $\mathrm{CaHPO}_{4} \cdot 2 \mathrm{H}_{2} \mathrm{O} \mathrm{I}_{7} \cdot \mathrm{I} \mathrm{g}, \mathrm{KH}_{2} \mathrm{PO}_{4} \mathrm{I} 3.3 \mathrm{~g}, \mathrm{NaCl} 8.67 \mathrm{~g}, \mathrm{MgSO}_{4} . \mathrm{H}_{2} \mathrm{O} 2.67 \mathrm{~g}, \mathrm{FeSO}_{2} \cdot 7 \mathrm{H}_{2} \mathrm{O}$ $670 \mathrm{mg}, \mathrm{MnSO}_{4} .4 \mathrm{H}_{2} \mathrm{O} 270 \mathrm{mg}, \mathrm{ZnSO}_{4} \cdot 7 \mathrm{H}_{2} \mathrm{O}$ I $30 \mathrm{mg}, \mathrm{KI} 37 \mathrm{mg}, \mathrm{CuSO}_{4} \cdot 5 \mathrm{H}_{2} \mathrm{O}$ I6 mg. The vitamin supplement supplied $(\mathrm{mg} / \mathrm{kg}$ diet): cholecalciferol $0 \cdot 16$, menaphthone 20 , retinol 20 , $\alpha$-tocopheryl acetate 20 , biotin 0.80 , pteroylmonoglutamic acid 6 , thiamin hydrochloride I 2 , pyridoxine hydrochloride 16 , riboflavin 24 , calcium pantothenate 60 , nicotinic acid 160 , cyanocobalamin 0.08 .

The sources of dietary fibre were wheat bran and wheat straw, both coarsely or finely ground, and finely-milled bagasse. They were incorporated into the basal diet at the expense of maize starch. After mixing, the diets were granulated. On most occasions the fibre source was added at the rate of $100 \mathrm{~g} / \mathrm{kg}$ diet. In Expt 3 wheat bran and wheat straw were assayed for their contents of dietary fibre (i.e. total unavailable carbohydrate plus lignin) by the method of Southgate (1969). Ground wheat straw was added to the basal diet at the rate of $45.3 \mathrm{~g} / \mathrm{kg}$ thus providing the same amount of dietary fibre as did $100 \mathrm{~g}$ wheat bran $/ \mathrm{kg}$.

Where sterilized diets were needed they were packed into plastic bags, sealed under vacuum and irradiated at $5 \mathrm{Mrad}$ from a ${ }^{60} \mathrm{Co}$ source. Autoclaved bran was prepared by spreading the material on shallow stainless-steel trays, covering with nylon sheets and heating in an autoclave at $121^{\circ}$ for $15 \mathrm{~min}$. It was dried in an air-flow at $40-45^{\circ}$ for $14 \mathrm{~h}$.

Measurement of gut dimensions. For gut weight and length determinations the birds were killed by breaking the neck and the entire small intestine was dissected out, washed free of its contents, blotted dry and weighed, and its length was recorded. The method of intestinal volume measurement of Hallsworth \& Coates (I962) was found unsuitable as the dead gut shed considerable portions of mucosa and this led to over-estimation of gut volumes. An in vivo method was devised in which the volume was measured in anaesthetized chicks after an overnight fast. The small intestine was cannulated in situ and its contents were washed out with warm physiological saline $\left(8.5 \mathrm{~g} \mathrm{NaCl} / 1\right.$ at $\left.40^{\circ}\right)$. The duodenal cannula was then connected to a source of physiological saline coloured by the addition of Orange $G(5 \mathrm{~g} / \mathrm{l})$ which was passed through the intestine until it appeared at the severed ileum, the volume of coloured saline that had passed being recorded.

Histology of the gut. The gut was fixed in vivo under diethyl ether anaesthesia to minimize distortion. The aorta was cannulated and the vessels were washed out with warm physiological saline followed by Bouin's fluid, when the gut tissue became rapidly fixed. Small pieces were removed from the duodenum, near the yolk stalk, approximately $100 \mathrm{~mm}$ distal to the ileo-caecal junction, mid-caecum, caecal tonsil and colon; and fixed for an additional $18 \mathrm{~h}$ in Bouin's fluid. They were embedded in paraffin, sectioned at $4 \mu \mathrm{m}$ and stained with 
haematoxylin and eosin. Measurements of villus length and width and the thickness of muscularis mucosa and externa were made with an eye-piece scale and a stage-micrometer and the lamina propria, villus and caecal tonsil areas were determined using an eye-piece graticule. The lymphoid area and the number of follicles in the caecal tonsil were recorded in a single section.

Statistical treatment. The weight, length and volumes of the small intestines were calculated in terms of metabolic body-weight $\left(\mathrm{kg}^{0 \cdot 75}\right)$. The values for body-weight, FCE and dimensions of the small intestine were subjected to analysis of variance. The standard errors given were generally based on the variation between replicate groups of chicks. For the histometric results the significance of differences between the two treatments was examined by Student's $t$ test.

\section{Plan of experiments}

All experiments except the preliminary test lasted for 4 weeks. The birds were individually weighed at the end of each week. Food consumption was recorded and the food conversion efficiency ( $g$ weight gained/g food eaten; FCE) was calculated.

Preliminary experiment. This was an exploratory test to compare growth for 3 weeks after hatching of duplicate groups of ten chicks given the purified diet alone or supplemented with coarse or fine bran, coarse wheat straw or finely-milled bagasse.

Expts I and 2. Birds given the diet with coarse bran in the preliminary test achieved a somewhat higher body-weight than the other groups. Two further experiments were done to establish whether or not this unexpected growth-promoting effect of bran was reproducible. In each, six groups of ten birds received the basal diet with or without the supplement of coarse bran.

Expt 3. To ascertain whether the growth-promoting action of bran was associated with its fibre content a diet was compounded in which finely-milled wheat straw provided the same amount of dietary fibre as was present in the diet supplemented with bran. Four groups of ten chicks were used on each treatment. Growth and FCE were compared on the basal diet alone or supplemented with wheat straw or bran.

Expt 4 . This test was designed to investigate whether the extent of comminution of dietary fibre modified its effect on body-weight or gut structure. Four groups of ten chicks received the basal diet alone or supplemented with wheat straw, either coarsely ground or finely milled.

Expt 5. The response of chicks to the bran diet sterilized by gamma-radiation was tested with the intention of later investigation of the growth-promoting effect in a germ-free environment. Four cages of four birds received the sterilized diet with or without a bran supplement for 4 weeks (Expt $5 a$ ). When no difference in growth was observed between the birds on the two treatments a more extensive comparison was made (Expt $5 b$ ) in which triplicate groups of ten chicks received either untreated or irradiated diets with or without the bran supplement.

Expt 6. The effects of sterilization by heat or gamma-radiation on the growth-promoting properties of bran were compared. Triplicate groups of ten chicks received the basal diet alone, or supplemented with untreated, irradiated or autoclaved bran (Expt $6 b$ ). Concurrently four cages of four birds in a controlled-environment room received the same treatments (Expt $6 a$ ).

In Expts $2,5 b$ and $6 b$ measurements of gut weight, length and volume were made on some of the birds. In Expt 3 two groups from each treatment were taken for these measurements and at 5 weeks of age representative birds from the group given coarse wheat straw and their corresponding controls on the basal diet were used for histological investigations. 
Table 1. Effect on growth and food conversion efficiency ( $g$ weight gained/g food eaten; $F C E)$ of incorporating various sources of dietary fibre into a low-residue diet* for chicks

(Mean values for six groups of ten chicks (Expts I and 2) or four groups of ten chicks (Expts 3 and 4))

Expt no.†

(I)

(2)

(3)

(4)
Source of fibre

None

Coarse wheat bran ( $100 \mathrm{~g} / \mathrm{kg}$ diet)

Least significant difference at $P<0.05$ SE of a mean

None

Coarse wheat bran (100 g/ $\mathrm{kg}$ diet)

Least significant difference at $P<0.05$ SE of a mean

None

Coarse wheat bran ( $100 \mathrm{~g} / \mathrm{kg}$ diet)

Finely-milled wheat straw $(45.3 \mathrm{~g} / \mathrm{kg}$ diet $\ddagger)$

Least significant difference at $P<0.05$ SE of a mean

None

Coarse wheat straw (100 g/ $\mathrm{kg}$ diet)

Finely-milled wheat straw ( $100 \mathrm{~g} / \mathrm{kg}$ diet)

Least significant difference at $P<0.05$ SE of a mean

$\begin{array}{ll}\begin{array}{c}\text { Body-wt } \\ (\mathrm{g})\end{array} & \text { FCE } \\ 334 & 0.589 \\ 342 & 0.624 \\ 10.9 & 0.024 \\ 3.48 & 0.008 \\ 367 & 0.570 \\ 391 & 0.601 \\ 18.6 & 0.023 \\ 5.89 & 0.007 \\ 372 & 0.642 \\ 394 & 0.634 \\ 380 & 0.610 \\ 25.5 & 0.044 \\ 8.28 & 0.014 \\ 337 & 0.637 \\ 317 & 0.638 \\ 350 & 0.631 \\ 28.5 & 0.032 \\ 8.92 & 0.010\end{array}$

* For details of diets, see p. 64 .

$\dagger$ For details of procedures, see p. 65 .

$\ddagger$ Contains the same concentration of dietary fibre as a diet with bran at $100 \mathrm{~g} / \mathrm{kg}$.

\section{RESULTS}

\section{Growth and FCE}

Preliminary experiment. There was an increase in growth of the birds given the coarse-bran diet and in one group of chicks given the fine-bran diet. Growth on the wheat-straw diet was poorer. The values for FCE were little affected by the addition of fibre except that they were lower on the bagasse diet. Although the increase in growth of birds given the coarse-bran diet was not statistically significant it seemed worthy of further investigation.

Expts I and 2. On both occasions the FCE was markedly improved by the bran supplement (Table I). Growth was also improved, although to a non-significant extent in Expt 1.

Expt 3 . The sample of bran contained $399 \mathrm{~g}$ unavailable carbohydrate $/ \mathrm{kg}$ and the wheat straw $880 \mathrm{~g} / \mathrm{kg}$. Thus $45.3 \mathrm{~g}$ wheat straw $/ \mathrm{kg}$ diet was included to provide the same amount of dietary fibre as $100 \mathrm{~g}$ bran $/ \mathrm{kg}$ diet. Table I shows the effect of giving the three diets on growth and FCE. As before, inclusion of bran in the low-residue diet improved growth, but the diet containing wheat straw supported growth only marginally better than that on the unsupplemented diet. FCE was poorer on the wheat-straw diet than on either of the other two.

Expt 4. There was an indication that the diet containing coarsely-milled wheat straw supported poorer growth than a comparable diet with finely-milled wheat straw (Table I). There was virtually no difference between FCE on the three diets.

Expts 5 and 6. It is apparent from the results in Table 2 that although the birds given untreated bran supplements were on every occasion heavier than those on the unsupplemented diet, the growth-promoting property of bran was destroyed by irradiation. Destruction occurred when the whole diet was irradiated (Expt 5) or when the bran was irradiated 
Table 2. Effects of sterilization by gamma-radiation or heat on the growth-promoting action for chicks of a supplement of $100 \mathrm{~g}$ wheat bran $/ \mathrm{kg}$ with a low-residue diet*

(Values are mean body-weights (g) at 4 weeks of age)

\begin{tabular}{|c|c|c|c|c|c|c|c|c|c|}
\hline \multirow{3}{*}{$\begin{array}{l}\text { Expt } \\
\text { no. }\end{array}$} & \multirow{3}{*}{$\begin{array}{l}\text { No. of } \\
\text { birds and } \\
\text { replicates }\end{array}$} & \multicolumn{4}{|c|}{$\begin{array}{c}\text { Non-irradiated } \\
\text { diet: } \\
\text { supplement }\end{array}$} & \multirow{2}{*}{\multicolumn{2}{|c|}{$\begin{array}{c}\text { Irradiated } \\
\text { diet: } \\
\text { Supplement }\end{array}$}} & \multirow{3}{*}{$\begin{array}{c}\text { Least } \\
\text { significant } \\
\text { difference } \\
\text { at } P<0.05\end{array}$} & \multirow{3}{*}{$\begin{array}{c}\text { SE } \\
\text { of a } \\
\text { mean }\end{array}$} \\
\hline & & & Untreated & Heated & Irradiated & & & & \\
\hline & & None & bran & bran & bran & None & Bran & & \\
\hline $5 a$ & $4 \times 4$ & - & - & - & - & 377 & 372 & $36 \cdot 3$ & 10.48 \\
\hline $5 b$ & $3 \times 10$ & 325 & 371 & - & - & 359 & 345 & $23 \cdot 3$ & $7 \cdot 13$ \\
\hline $6 a$ & $4 \times 4$ & 371 & 389 & 362 & 372 & - & - & $28 \cdot 7$ & $9 \cdot 31$ \\
\hline $6 b$ & $3 \times 10$ & 385 & 407 & 395 & 385 & - & - & $31 \cdot 0$ & $9 \cdot 5^{2}$ \\
\hline
\end{tabular}

separately before incorporation (Expt 6). Autoclaved bran supported poorer growth than the unheated material.

\section{Characteristics of the intestines}

The effects of dietary fibre on weight, length and volume of the small intestine were small and inconsistent. There was a significant increase in intestinal volume in the birds given bran in Expt 2, but this was not confirmed in Expt 5. No effect of bran on weight or length of the gut was observed in Expt 2, but in Expt $6 b$ the weight per unit length of intestine was significantly greater in the birds on the bran diet. In the experiment with coarse and fine wheat straw the only significant effect was a lowering of the gut weight in birds given the supplement of fine wheat straw. Intestinal volume was increased by the supplement of coarse wheat straw, but not significantly.

In general the villus height and the thickness of muscularis mucosa and externa were greater and the lumen area smaller in the birds given the supplement of coarse wheat straw, but only two of these differences, both in the upper ileum, reached statistical significance. There was a marked increase in lymphoid area and the number of lymphoid follicles in the caecal tonsil of the supplemented birds. No evidence of abrasion was observed in any of the sections from either group.

\section{DISCUSSION}

These studies were planned with the expectation that inclusion of dietary fibre at the expense of starch would reduce the nutritive value of the experimental diet. Not only was the energy density of the diet diluted by unavailable carbohydrate but the transit time of the food through the gastrointestinal tract was likely to be hastened by the presence of fibre, affording less time for its digestion and absorption by the chick. The finding that a diet containing wheat bran supplying approximately $40 \mathrm{~g}$ unavailable carbohydrate/ $\mathrm{kg}$ supported better growth than the corresponding unsupplemented diet was therefore surprising. The improvement in growth was small, but it was consistently observed in the seven experiments in which bran was given; in some of these FCE was also better. When the results from five comparable experiments were combined, analysis of variance showed that although the magnitude of the growth response to bran varied considerably between experiments the over-all mean $(6.85 \%)$ was highly significant $(P<0.001)$.

The growth-promoting property of bran was apparently not directly due to its fibre 
content since a diet containing enough wheat straw to provide an equivalent amount of fibre did not support better growth than the low-residue basal diet. The possibility was considered that the growth response to bran was mediated through the gut microflora, as is the case with fish-solubles (Harrison \& Coates, 1972). This might have been tested in an experiment with germ-free shicks, but the investigation could not be pursued because sterilization of the diet either by gamma-radiation or by autoclaving resulted in the loss of its growth-promoting property. It can be inferred therefore that bran contains a chick growth factor that is destroyed on irradiation or by heat. No attempt has yet been made to characterize it further.

When sources of dietary fibre other than bran were tested, their effects on growth and FCE depended to some extent on the relative comminution of the fibre (Table I). For instance, the diet supplemented with coarsely-milled wheat straw supported poorer growth than the corresponding low-residue diet but FCE was not affected. Conversely, a supplement of finely-milled bagasse or wheat straw had little effect on growth but markedly reduced FCE. Apparently when the fibrous supplement was finely milled the birds were able to eat enough diet to satisfy their requirements for energy and to maintain their growth rate at the same level as that of their hatch-mates given the low-residue diet. The coarse wheat straw probably made the diet unpalatable and difficult to eat, so that they were unable to consume enough to support normal growth. Nevertheless, at the lower intake FCE was much the same as that of birds on the basal diet.

One of the most important physical properties of dietary fibre is its capacity to hold water and thus increase the bulk of the intestinal contents. If there were a consequent increase in dimensions of the gut absorption of nutrients might be improved. Conversely, if the abrasive nature of some fibres damaged the mucosa, absorption could be impaired. No conclusive evidence was obtained on either of these points in these experiments. Such differences as were observed in intestinal volume, weight and length between birds given low-residue and fibre-supplemented diets were inconsistent and there was no apparent correlation of any of tnese effects with growth or FCE.

Measurements made on sections of intestine from a few birds suggested that those given coarse wheat straw had longer villi, greater thickness of the two muscularis layers and a smaller lumen area than their corresponding controls, although only two of the observed differences were significant. In these birds also the caecal tonsil had a thinner muscularis externa, a greater area of lymphoid tissue and a larger number of lymphoid follicles. These differences, if substantiated, could be of nutritional importance. The dimensions of the villi and the muscularis layers might be correlated with absorptive capacity or digestive efficiency and the number of lymphoid follicles with the constitution of the caecal microflora. However, the histological investigation was of an exploratory nature only, and would need to be considerably extended before any firm hypotheses are advanced.

The authors are grateful to their colleague Dr D. Hewitt for help with the statistical analysis. S.N.H. was the recipient of a Commonwealth Scholarship for postdoctoral research. 


\section{REFERENCES}

Annison, E. F., Hill, K. J. \& Kenworthy, R. (1968). Br. J. Nutr. 22, 207. Eastwood, M. A. (1973). Proc. Nutr. Soc. 32, 137.

Farrell, D. J. \& Johnson, K. A. (I970). Anim. Prod. 14, 209.

Gasaway, W. C. (1976a). Comp. Biochem. Physiol. 53 A, 109.

Gasaway, W. C. (1976b). Comp. Biochem. Physiol. 53 A, 115.

Hallsworth, E. G. \& Coates, J. T. (I962). J. agric. Sci., Camb. 58, I 53.

Harrison, G. F. \& Coates, M. E. (1972). Br. J. Nutr. 28, 213.

Hoover, W. H. \& Clarke, S. D. (1972). J. Nutr. ro2, 9.

Hoover, W. H. \& Heitmann, R. N. (1972). J. Nutr. 102, 375.

Johnson, J. L. \& McBee, R. H. (1967). J. Nutr. 9r, 540.

Southgate, D. A. T. (1969). J. Sci. Fd Agric. 20, 331.

Yang, M. G., Manoharan, K. \& Young, A. K. (1969). J. Nutr. 97, 260. 